\title{
Biological Control Efficiency of Fusarium Wilt of Tomato by Nonpathogenic Fusarium oxysporum Fo-B2 in Different Environments
}

\author{
Masahiro Shishido, Chika Miwa, Toshiyuki Usami, Yoshimiki Amemiya, and Kenneth B. Johnson
}

\begin{abstract}
First, third, and fourth authors: Department of Bioproduction Science, Faculty of Horticulture, Chiba University, 648 Matsudo, Matsudo-shi, Chiba 271-8510, Japan; second author: Graduate School of Science and Technology, Chiba University, Yayoicho-1-33, Inage, Chiba-shi, Chiba 263-8522, Japan; fifth author: Department of Botany and Plant Pathology, Oregon State University, Corvallis 97331-2902. Current address of C. Miwa: Chiba Horticultural Experiment Station, 1762 Yamamoto, Tateyama-shi, Chiba 294-0014, Japan. Accepted for publication 18 May 2005.
\end{abstract}

\section{ABSTRACT}

Shishido, M., Miwa, C., Usami, T., Amemiya, Y., and Johnson, K. B. 2005. Biological control efficiency of Fusarium wilt of tomato by nonpathogenic Fusarium oxysporum Fo-B2 in different environments. Phytopathology 95:1072-1080.

Efficiency of nonpathogenic Fusarium oxysporum Fo-B2 for the biological control of Fusarium wilt of tomato, caused by F. oxysporum $\mathrm{f}$. sp. lycopersici CU1, was examined in different environments: a growth chamber with sterile soil-less medium, a greenhouse with fumigated or nonfumigated soil, and nonfumigated field plots. Inoculation of Fo-B2 onto tomato roots significantly reduced the severity of disease, but the efficiency of disease suppression decreased as the experimental environment became less controlled. Relationships between the recovery of FoB2 from hypocotyls and the disease severity indicated that the biocontrol agent was most effective when it colonized vascular tissues intensively. Moreover, the degree of Fo-B2 colonization was greatly reduced when the seedlings were grown in nonfumigated soil. Dose-response models (negative exponential, hyperbolic saturation, and logistic) were fit to observed data collected over a range of inoculum densities of the pathogen and the antagonist; the logistic model provided the best fit in all environments. The ratios of an 50\% effective dose parameter for Fo-B2 to that of CU1 increased as the environment became less controlled, suggesting that environmentally related efficiency reduction impacted the antagonist more than the pathogen. The results suggest that indigenous soil microbes were a primary factor negatively influencing the efficiency of Fo-B2. Therefore, early establishment of the antagonist in a noncompetitive environment prior to outplanting could improve the efficacy of biological control.
Biological suppression of plant disease has been promoted as a means to achieve improved, sustainable crop production systems that are less reliant on chemical inputs (1). Successful biological control systems commonly employ naturally occurring, antagonistic microorganisms that are able to reduce the activities of plant pathogens. Such antagonists (or biocontrol agents) can compete with pathogens for nutrients, inhibit pathogen growth by secreting antibiotics, or reduce pathogen populations through parasitism. In addition, some of these microorganisms induce resistance in host plants, which enhances the plant's ability to defend itself from pathogen attack (6).

Nonpathogenic strains of Fusarium spp. have suppressed soilborne diseases caused by pathogenic Fusarium spp. under greenhouse and field conditions (4,10-12,15-18). As with other soilborne diseases, biological control of Fusarium wilt usually involves inundative (massive) inoculation of propagules of an antagonist isolate. Therefore, selection of effective antagonists typically is based on results of experiments where both pathogen and biocontrol agent candidates have been evaluated over a range of propagule densities (12). For example, a nonpathogenic Fusarium oxysporum isolate, Fo-B2 has been shown to reduce disease severities of Fusarium wilt of tomato under greenhouse conditions (3). However, the rates of disease suppression by FoB2 often were variable, and satisfactory disease control was achieved only when the initial dose of Fo-B2 was more than 10 times that of the pathogen (19).

Corresponding author: M. Shishido; E-mail address: shishido@faculty.chiba-u.jp

DOI: 10.1094/PHYTO-95-1072

(C) 2005 The American Phytopathological Society
In recent years, epidemiological dose-response models have been used to describe and summarize the effects of biocontrol agents on plant disease development $(7,10,14,20)$. These models can identify and characterize parameters that contribute to the relative efficacy of biological control. For example, Johnson (7) proposed an asymptote parameter that defines a proportion of a pathogen population that cannot be affected by an antagonist population; thus, the magnitude of this parameter greatly influences the efficacy of the biocontrol system. Models based on the hyperbolic saturation (HS) $(5,14,20)$ and on the logistic (LG) functions $(10,20)$ have been used to estimate a $50 \%$ effective dose $\left(\mathrm{ED}_{50}\right)$ for the pathogen and the biocontrol agent as well as the relative efficiency by their ratio. Comparison of such parameters estimated from experiments with differing antagonist, host, and pathogen genotypes has aided in the elucidation and understanding of factors affecting the quality of the antagonistic interaction $(8,20)$.

In this article, we characterize the effect of four environments on the efficiency of nonpathogenic $F$. oxysporum Fo-B2 for suppression on Fusarium wilt of tomato. Our goal was to better understand how environmental complexity contributes to variation in the effectiveness of this biocontrol system.

\section{MATERIALS AND METHODS}

Pathogen and biocontrol agent. The causal agent of Fusarium wilt, F. oxysporum Schlechtend.:Fr. f. sp. lycopersici race 1 strain CU1, was isolated originally from a tomato host grown in Chiba, Japan, and subsequently maintained in a culture collection of the Plant Pathology Laboratory, Chiba University. Nonpathogenic F. oxysporum Fo-B2 was selected as the biocontrol agent. This 
strain is a benomyl-resistant derivative of Fo-304, which was isolated from the rhizosphere of a healthy tomato grown in the experimental field of Chiba University. The suppression of $\mathrm{Fu}-$ sarium wilt by Fo-B2 is similar to Fo-304 (3); also, root inoculations with Fo-B2 have been shown to reduce the severity of tomato powdery mildew (13). Prior to initiating this study, stock cultures of CU1 and Fo-B2 were root inoculated onto tomato seedlings. Each fungus then was re-isolated from surface-sterilized tomato stem tissues and a single-conidium isolate was obtained and used to produce inocula.

Inoculum production and inoculation method. Bud-cell suspensions of CU1 and Fo-B2 were prepared by culturing each fungus for 1 week in Czapek broth medium $\left(\mathrm{NaNO}_{3}, 2.0 \mathrm{~g}\right.$; $\mathrm{K}_{2} \mathrm{HPO}_{4}, 1.0 \mathrm{~g} ; \mathrm{MgSO}_{4} \cdot 7 \mathrm{H}_{2} \mathrm{O}, 0.5 \mathrm{~g} ; \mathrm{KCl}, 0.5 \mathrm{~g} ; \mathrm{FeSO}_{4} \cdot 7 \mathrm{H}_{2} \mathrm{O}$, $0.01 \mathrm{~g}$; glucose, $30.0 \mathrm{~g}$; and $\mathrm{dH}_{2} \mathrm{O}, 1,000 \mathrm{ml}$ ) on a rotary shaker at $25^{\circ} \mathrm{C}$. The resulting bud-cell suspensions were filtered through cheesecloth to remove mycelial fragments, washed by centrifugation $(6,000 \times g$ for $15 \mathrm{~min})$, and resuspended in sterile distilled water. The cell density of the bud-cell suspension was determined with aid of a hemacytometer, and concentrations used as experimental treatments were achieved by diluting with sterile distilled water.

Characterization of the effect of environment on the efficiencies of Fo-B2 and CU-1 required precise inoculum dose treatments. In this regard, preliminary experiments were conducted to compare the method of mixing fungal bud-cells into soil ("soil inoculation") to dipping seedling roots in a bud-cell suspension ("root inoculation"). For soil inoculation, the bud-cell suspension of FoB2 or CU1 was mixed with soil medium consisting of $50 \%$ vermiculite and $50 \%$ steam pasteurized field soil at the final density of $5 \times 10^{4}$ bud-cells/g of fresh soil. Density of CFU of the fungal isolates in the soil medium was examined immediately and at 1 week after inoculation by standard soil dilution plating onto Komada's medium (9) with or without benomyl (10 mg/liter). In addition, 2-week-old seedlings of susceptible tomato cv. Ponderosa were transplanted in the inoculated soil medium. At 1 week after transplanting, each seedling was uprooted and the root mass was homogenized with mortar and pestle followed by serial dilution plating onto Komada's medium.

For root inoculation, 2-week-old seedling roots were dipped in a bud-cell suspension $\left(1 \times 10^{5}\right.$ bud- cells $\left./ \mathrm{ml}\right)$ of CU1 or Fo-B2 for $10 \mathrm{~min}$. In another treatment, roots were first dipped in the Fo-B2 suspension $\left(1 \times 10^{5}\right.$ bud-cells $\left./ \mathrm{ml}\right)$ for $10 \mathrm{~min}$, then followed by CU1 suspension for $10 \mathrm{~min}\left(1 \times 10^{5}\right.$ bud-cells $\left./ \mathrm{ml}\right)$. Inoculated seedling root masses were homogenized immediately and dilution plated as described above. The root inoculation method resulted in a coefficient of variation of recovered CFU counts that was two to three times lower than that for soil inoculation (Table 1). Consequently, root inoculation was used in subsequent dose-response experiments.
Growth chamber experiment. Seed of tomato cv. Ponderosa were sown in plastic trays ( 52 by 31 by $6 \mathrm{~cm}$ deep) containing autoclaved vermiculite placed in a lighted growth chamber (MLR-350HT; Sanyo Electric Co., Tokyo) set to a temperature of $25^{\circ} \mathrm{C}$ during the day $(16 \mathrm{~h})$ and $18^{\circ} \mathrm{C}$ at night $(8 \mathrm{~h})$. At 2 weeks after emergence, the seedlings were removed from the tray, and roots were gently washed with distilled water and suspended in a bud-cell suspension of Fo-B2 $\left(0,1 \times 10^{4}, 1 \times 10^{5}, 1 \times 10^{6}\right.$, or $1 \times$ $10^{7}$ bud-cells $/ \mathrm{ml}$ ) for $10 \mathrm{~min}$. Successively, each seedling was dipped in the bud-cell suspension of CU1 $\left(1 \times 10^{4}, 1 \times 10^{5}\right.$, or $1 \times$ $10^{6}$ bud-cells $/ \mathrm{ml}$ ) for $10 \mathrm{~min}$, then planted in a $200-\mathrm{ml}$ paper cup filled with sterile vermiculite. Seedlings were returned to the growth chamber (same conditions) and treated weekly with a filter-sterilized liquid fertilizer (Hyponex, 5:10:5 N:P:K, 0.1\% [vol/vol]; Hyponex Japan, Osaka, Japan) until the end of the bioassay. The combinations of the pathogen and the antagonist densities resulted in 15 treatments that were arranged as a completely randomized design with eight replicate plants. In addition, eight nonpathogen-inoculated seedlings were placed in the chamber as healthy controls.

Beginning a week after inoculation, external symptoms of Fusarium wilt (wilting and yellowing leaves) were assessed weekly for a period of 4 weeks. Disease severity was defined as the proportion of leaves with symptoms compared with the total number of leaves. At the end of the 4-week period, the development of Fusarium wilt was confirmed by visually assessing vascular discoloration of hypocotyl cross-sections cut $1 \mathrm{~cm}$ below the point of cotyledon attachment. In addition, vascular colonization by Fo-B2 was examined by sampling a 5-mm-long hypocotyl segment. Each segment was surface sterilized by immersion in $70 \%$ ethanol for $1 \mathrm{~min}$, followed by rinsing in sterile water, and placed on a petri plate containing Komada's medium (9) amended with benomyl (10 mg/liter). The plates were incubated at $25^{\circ} \mathrm{C}$ for 1 week. Vascular colonization of Fo-B2 was scored positive when a typical $F$. oxysporum colony developed from the hypocotyl segment on the plate. The growth chamber experiment was conducted twice.

Greenhouse experiment. Seed of tomato cv. Ponderosa were grown in sterile vermiculate until 2 weeks after emergence, then inoculated with CU1 and Fo-B2 using the same protocol and propagule densities as described for the growth chamber experiment. Inoculated seedlings were planted into $900-\mathrm{ml}$ ceramic pots (three plants to a pot, $15 \mathrm{~cm}$ in diameter) filled with a soil-based medium consisting of 5-mm-mesh-sieved loam soil (Andosols; $58.0 \%$ sand, $35.2 \%$ silt, and $6.8 \%$ clay) and vermiculite mixed in a ratio of $7: 3$. The source of the loam was the Chiba University Experimental Farm. After mixing with vermiculite, half of the soil medium was fumigated with chloropicrin $(0.01 \%$ [vol/vol] fumigant per soil medium; Nippon Kayaku, Co., Tokyo); the other half of the medium was left untreated. Properties of the soil medium

TABLE 1. Recovery of Fusarium oxysporum isolates from soil or root of tomato as influenced by inoculation methods ${ }^{\mathrm{a}}$

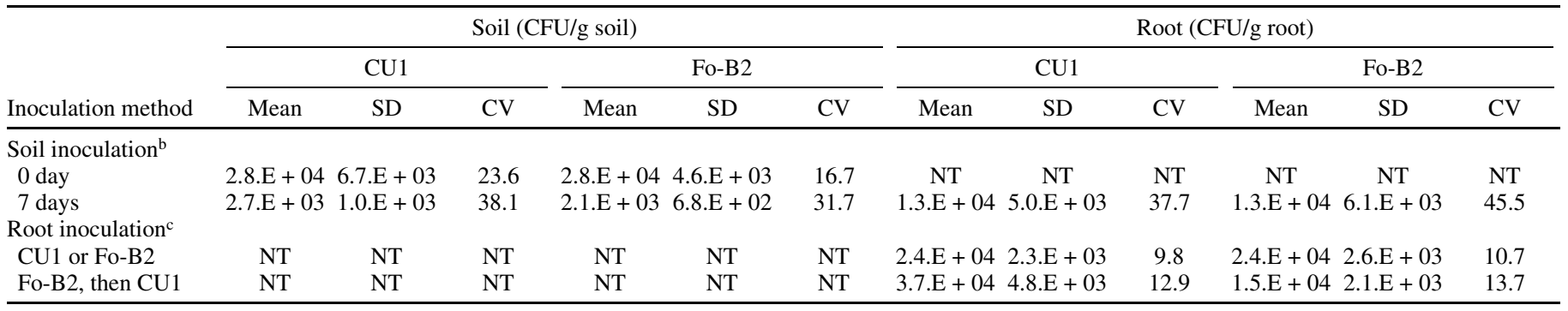

${ }^{a} \mathrm{CFU}$ were determined by a standard dilution plating with Komada's medium, and recovery of Fo-B2 was determined with Komada's medium amended with $10 \mathrm{mg} /$ liter. $\mathrm{SD}=$ standard deviation $(n=6), \mathrm{CV}=$ coefficient of variability $(\%)$, and $\mathrm{NT}=$ not tested.

${ }^{b}$ Soil inoculated with CU1 or Fo-B2 at $5 \times 10^{4}$ bud-cell/g of soil for 0 day or 7 days.

${ }^{\mathrm{c}} \mathrm{CU} 1$ or Fo-B2 $=$ seedling root dipped in CU1 or Fo-B2 suspension $\left(1 \times 10^{5}\right.$ bud-cell/ml $)$ and Fo-B2, then CU1 $=$ seedling root dipped in Fo-B2 suspension $(1 \times$ $10^{5}$ bud-cell/ml) followed by CU1 suspension $\left(1 \times 10^{5}\right.$ bud-cell $\left./ \mathrm{ml}\right)$. Seedling root masses were homogenized immediately after the inoculation and dilution plated. 
were as follows: bulk density, $0.98 \mathrm{~kg} / \mathrm{liter}$; $\mathrm{pH}$, 6.0; CEC, $213 \mathrm{mmol} / \mathrm{kg}$; total $\mathrm{C}, 21 \mathrm{~g} / \mathrm{kg}$; total $\mathrm{N}, 1.9 \mathrm{~g} / \mathrm{kg}$; available P, $40 \mathrm{mg} / \mathrm{kg}$; exchangeable $\mathrm{K}, 0.66 \mathrm{~g} / \mathrm{kg}$; exchangeable $\mathrm{Ca}, 2.6 \mathrm{~g} / \mathrm{kg}$; and exchangeable $\mathrm{Mg}, 0.42 \mathrm{~g} / \mathrm{kg}$.

Plants in the greenhouse were watered daily, and fertilized weekly with a liquid commercial fertilizer (Hyponex, 5:10:5 $\mathrm{N}: \mathrm{P}: \mathrm{K}, 0.1 \%$ [vol/vol]; Hyponex Japan). Greenhouse temperatures varied between 22 and $43^{\circ} \mathrm{C}$. Each combination of pathogen and antagonist density consisted of four replicate pots of three plants per pot arranged in a randomized complete block design. The full experiment comprised 30 treatment combinations: five dose levels of Fo-B2 (including noninoculated control), three dose levels of CU1, and either fumigated or nonfumigated soil. In addition, four pots (12 plants) of nonpathogen-inoculated seedlings were planted and maintained as healthy controls. Disease severity of Fusarium wilt was assayed as described in the growth chamber experiment. The greenhouse experiment was conducted twice.

Field experiment. The field experiment was conducted using concrete-frame plots $(2.2$ by $3.2 \mathrm{~m} / \mathrm{plot})$ located at the Chiba University Experimental Farm in Matsudo-shi, Japan. All plots were used for cucumber cultivation in the previous season and had been fallow for 6 months. One month before the experiment, a commercial organic fertilizer (Temporon, including ligno-cellulose, fumic acid, $\mathrm{Ca}, \mathrm{Mg}, \mathrm{Mn}$, and B; Mitsubishi-shoji, Tokyo), was applied at a rate of $5 \mathrm{~kg}$ per plot and thoroughly incorporated. Two-week-old seedlings of tomato cv. Ponderosa were root inoculated as described for the growth chamber experiment and planted immediately into the center area of each plot in three rows spaced $50 \mathrm{~cm}$ apart with a $30-\mathrm{cm}$ spacing between plants. Groups of three seedlings composed the experimental unit, and these units were planted in a randomized complete block design with four blocks of 15 treatment combinations (five dose levels of FoB2 and three dose levels of CU1). In addition, an experimental unit of nonpathogen- or non-Fo-B2-inoculated seedlings also was planted in each block. Plants were grown in the plots for a period of 4 weeks and received supplemental irrigation as needed. To protect seedlings from insect injuries and airborne diseases, a foliar spray of insecticide-fungicide (Ortran C, acephate $300 \mathrm{ppm}$ and triforine $150 \mathrm{ppm}$; Sumika-Takeda Engei, Tokyo) was applied every other week. Temperature ranged from 18 to $34^{\circ} \mathrm{C}$, and no severe damage by weather or insects was observed during the cultivation. Disease severity of Fusarium wilt was assayed as described before. The field experiment was conducted once.

Data analysis. Disease severity data for the pathogen doseresponse and the biocontrol dose-response were fit to three nonlinear equations: negative exponential (NE), HS, and LG. The mathematical form of each model and the parameters that were estimated are presented in Table 2. Each model contains a pathogen and a biocontrol agent component, and relates the incidence of disease $(Y)$ to pathogen dose $(x)$ and to the proportion of pathogen dose rendered ineffective $\left(x_{i} / x\right)$ by the dose of the biocontrol agent $(z)$. Parameters in these models can define an asymptote (NE and HS models), an $\mathrm{ED}_{50}$ (HS and LG models), and a rate of change (NE and LG models). Asymptote parameters correspond to an upper limitation to disease for the pathogen or to pathogen inoculum suppression for the antagonist. $\mathrm{ED}_{50}$ parameters define the dose at which $50 \%$ of the maximum amount of disease (pathogen) or pathogen inoculum suppression (antagonist) occurs. Rate parameters determine the degree of response of the dependent variables (disease or pathogen inoculum suppression) with respect to changing the dose of either the pathogen or the biocontrol agent. Asymptote, rate, and $\mathrm{ED}_{50}$ parameters can be interpreted as measurements of efficiencies of a pathogen or a biocontrol agent in a given system $(10,14,20)$. Because every model contains four parameters, a recommended $(10,14,20)$ two-step parameterization was employed. The two parameters relating to the pathogen component of each model were determined first by fitting data from the treatments not amended with the antagonist. Subsequently, parameter estimates for the pathogen component were fixed as constants and used to estimate the two parameters for the biocontrol component of each equation.

Parameter estimation was performed by a nonlinear-least-squares procedure of Systat (version 9.0; SPSS, Inc., Chicago) using the Gauss-Newton method of iteration. Both raw (nontransformed) and log-transformed $\left(\log _{10}[x+1]\right)$ values of inoculum densities for the pathogen and the biocontrol agent were applied to fit the models. When no pathogen was inoculated, $x_{i} / x$ was defined as 0 . Fitted models were assessed by the residual mean square (RMS) and the coefficient of determination $\left(R^{2}\right)$ between observed values and predicted values. Each parameter was evaluated by the asymptotic standard error (ASE) and 95\% Wald confidence interval. Parameter estimates were considered significant $(P<0.05)$ when the range of this confidence interval did not include zero.

\section{RESULTS}

Effect of the pathogen and the antagonist on the severity of Fusarium wilt. Results of the first experiment, including 60 bioassays with various inoculum doses of the pathogen, $\mathrm{CU} 1$, and the antagonist, Fo-B2, for all four different environmental conditions, are summarized in Figure 1. For plants that received CU1 only, the disease severity of Fusarium wilt in the growth chamber ranged from 0.58 to 0.95 . The greenhouse environment with fumigation, the greenhouse without fumigation, and the field plots averaged 0.51 to $0.84,0.43$ to 0.81 , and 0.47 to 0.68 , respectively.

TABLE 2. Pathogen-biocontrol dose-response models expressing the proportion of disease $(Y)$ of Fusarium wilt as a function of the inoculum bud-cell density of Fusarium oxysporum f. sp. lycopersici $(x)$ and the biocontrol agent, nonpathogenic $F$. oxysporum Fo-B2 (z)

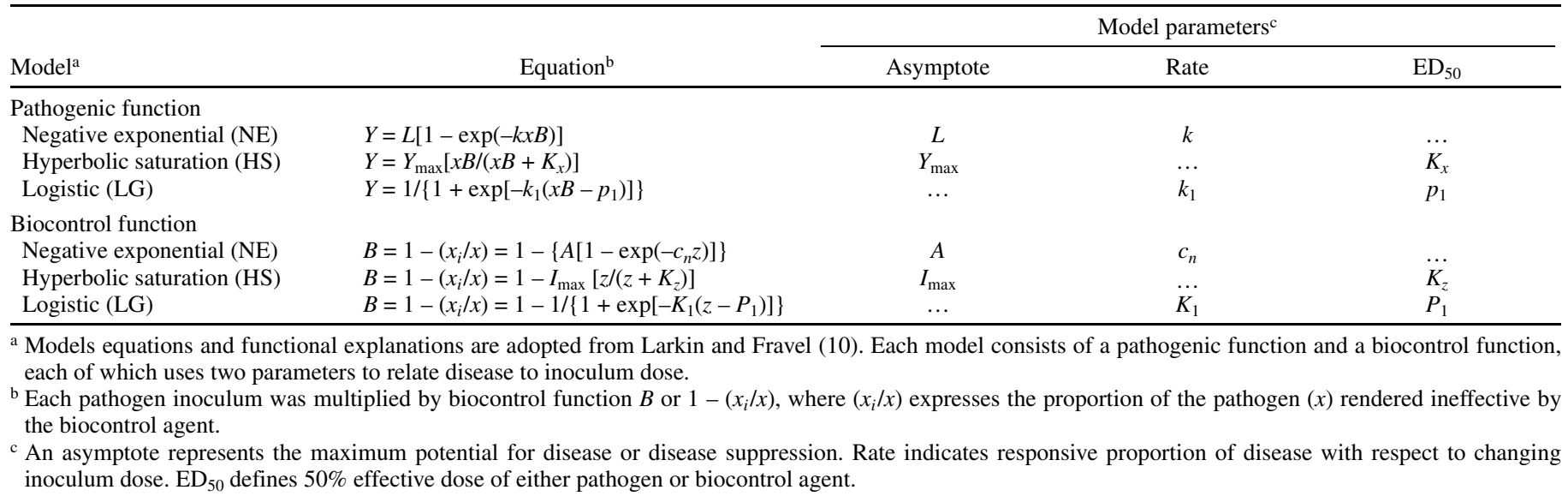


Disease suppression by Fo-B2 was observed for all cultural conditions, but rate of suppression varied among the environments. For example, when the disease suppression was expressed as a reduction relative to the pathogen-only control, Fo-B2 reduced disease severity in the growth chamber by 35 to $87 \%$. As with the effect of pathogen on disease severity, the effect of FoB2 on disease suppression was lessened as the environmental conditions became more complex. For example, in contrast to the growth chamber environment, disease suppression by Fo-B2 in the greenhouse was lessened to a range of 14 to $71 \%$ in fumigated soil and to a range of 14 to $56 \%$ with nonfumigated soil. The field experiment, representing the most complex environment, showed the smallest range of disease reduction by Fo-B2 (16 to 30\%). Overall, the main effect of either the pathogen or the antagonist dose was consistent within each environment (i.e., the higher doses of CU1 or the lower doses of Fo-B2 yielded a higher mean disease severity).

Modeling dose-response relationships in different environments. The disease severity and pathogen dose data from each cultural environment were described by the dose-response models.
Based on the RMS, the $R^{2}$ between the observed and predicted values and significance of parameters in the model, the NE, HS, and LG models each fit the data reasonably well, with the possible exception of the field experiment (Table 3). Under this cultural condition, the $R^{2}$ was reduced for all models and only the LG model exhibited two significant parameters, whereas the NE and HS models resulted in only one significant parameter (i.e., the asymptote). Asymptote parameters from the NE and HS models were between 0.887 and 0.932 in the growth chamber experiments, indicating a maximum disease potential of 89 to $93 \%$. Asymptote values were progressively lower for the other growth environments, with a low of 0.536 to 0.601 in the field test, indicating that maximum predicted disease in the field would be 54 to $60 \%$. Parameter values representing $\mathrm{ED}_{50}$ estimates differed between the $\mathrm{HS}$ and the $\mathrm{LG}$ models. Predicted $\mathrm{ED}_{50}$ values changed only slightly among the different cultural conditions with the HS model $\left(3.64\right.$ to $\left.7.13 \times 10^{3}\right)$, but were much lower in fumigated soil $\left(0.83\right.$ to $\left.1.07 \times 10^{4}\right)$ than nonfumigated soil $(1.62$ to $2.63 \times 10^{4}$ ) with the LG model. The parameter values obtained for each of the models generally confirmed that the growth cham-
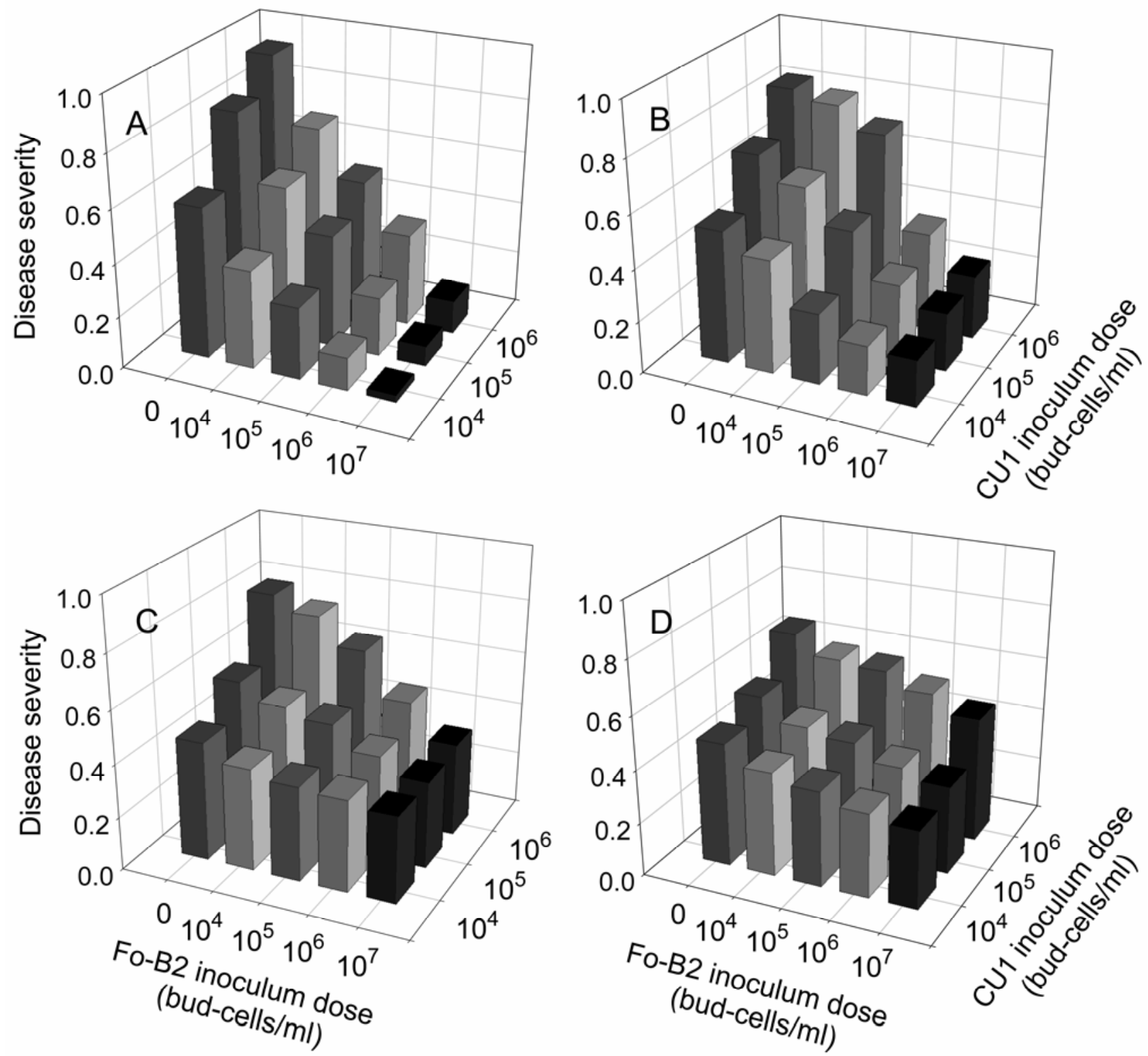

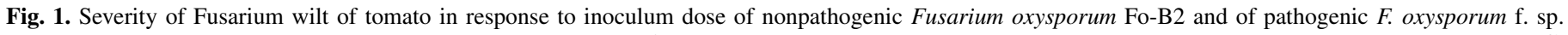

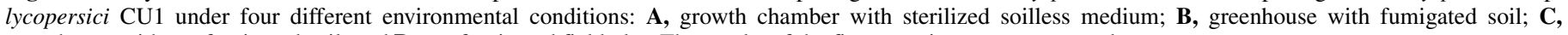
greenhouse with nonfumigated soil; and $\mathbf{D}$, nonfumigated field plot. The results of the first experiment are presented. 
ber environment was the most conducive to disease development, whereas the field environment was the least conducive.

To evaluate the efficiency of the biocontrol component of the pathosystem as influenced by the cultural environment, disease severity data were fit to the dose response models using the pathogen parameter values derived from the pathogen-only treatments. The results of regression analyses (Table 4) indicated that all of the biocontrol models described the responses observed in the growth chamber and in the greenhouse with fumigated soil. In contrast, for data obtained in the greenhouse with nonfumigated soil, the NE and the HS models provided only significant $(P<$ 0.05 ) asymptote parameters $\left(A\right.$ and $\left.I_{\max }\right)$. For the growth chamber and greenhouse with fumigated soil, the asymptote values indicated that potentially 99 to $100 \%$ of pathogen propagules could be rendered ineffective; for the field plot, the asymptote value declined to a maximum effectiveness of $74 \%$ (HS model).

The LG model, on the other hand, maintained good fitness to data obtained using nonfumigated soil with significant parameter estimates (Table 4), and this trend was similarly maintained in the field data. $\mathrm{ED}_{50}$ values of the biocontrol agent increased as the cultural conditions became less controlled for both the HS and LG models (Table 4), indicating that much higher doses of Fo-B2 were needed in the nonfumigated soils. Estimated $\mathrm{ED}_{50}$ values for Fo-B2 ranged from $2.52 \times 10^{3}$ (growth chamber) to $6.41 \times 10^{4}$

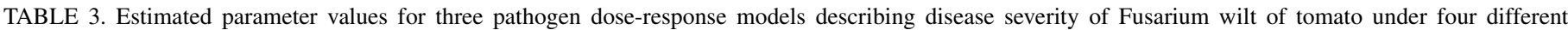
cultural conditions ${ }^{\mathrm{a}}$

\begin{tabular}{|c|c|c|c|c|c|c|c|c|c|c|c|c|}
\hline \multirow[b]{2}{*}{ Condition $^{\mathrm{b}}$} & \multicolumn{4}{|c|}{ Negative exponential (NE) model } & \multicolumn{4}{|c|}{ Hyperbolic saturation (HS) model } & \multicolumn{4}{|c|}{ Logistic (LG) model } \\
\hline & $L$ & $k$ & RMS & $R^{2}$ & $Y_{\max }$ & $K_{x}$ & RMS & $R^{2}$ & $k_{1}$ & $p_{1}$ & RMS & $R^{2}$ \\
\hline \multicolumn{13}{|l|}{ GC } \\
\hline \multirow[t]{2}{*}{ Exp. 1} & $0.887 *$ & $1.04 \mathrm{E}-4 *$ & & & $0.921 *$ & $6.28 \mathrm{E}+3 *$ & & & $1.000 *$ & $3.60 *$ & & \\
\hline & $(0.030)$ & $(0.15 \mathrm{E}-4)$ & 0.014 & 0.907 & $(0.032)$ & $(1.38 \mathrm{E}+3)$ & 0.013 & 0.915 & $(0.185)$ & $(0.196)$ & 0.013 & 0.919 \\
\hline \multirow[t]{2}{*}{ Exp. 2} & $0.912 *$ & $1.40 \mathrm{E}-4 *$ & & & $0.932 *$ & $3.64 \mathrm{E}+3 *$ & & & $1.000 *$ & $3.36^{*}$ & & \\
\hline & $(0.026)$ & $(0.19 \mathrm{E}-4)$ & 0.011 & 0.932 & $(0.028)$ & $(0.87 \mathrm{E}+3)$ & 0.010 & 0.935 & $(0.175)$ & $(0.213)$ & 0.011 & 0.929 \\
\hline \multicolumn{13}{|l|}{ GH-fum } \\
\hline \multirow[t]{2}{*}{ Exp. 1} & $0.766^{*}$ & $1.08 \mathrm{E}-4 *$ & & & $0.797 *$ & $6.14 \mathrm{E}+3^{*}$ & & & $0.871^{*}$ & $4.03^{*}$ & & \\
\hline & (0.039) & $(0.24 \mathrm{E}-4)$ & 0.012 & 0.901 & $(0.041)$ & $(1.99 \mathrm{E}+3)$ & 0.011 & 0.913 & $(0.170)$ & (0.191) & 0.009 & 0.928 \\
\hline \multirow[t]{2}{*}{ Exp. 2} & $0.781 *$ & $1.26 \mathrm{E}-4 *$ & & & $0.815^{*}$ & $5.24 \mathrm{E}+3^{*}$ & & & $0.892 *$ & $3.92 *$ & & \\
\hline & $(0.046)$ & $(0.30 \mathrm{E}-4)$ & 0.014 & 0.894 & $(0.043)$ & $(1.81 \mathrm{E}+3)$ & 0.011 & 0.912 & $(0.151)$ & $(0.170)$ & 0.007 & 0.951 \\
\hline \multicolumn{13}{|l|}{ GH-non } \\
\hline \multirow[t]{2}{*}{ Exp. 1} & $0.688 *$ & $1.05 \mathrm{E}-4 *$ & & & $0.725^{*}$ & $7.13 \mathrm{E}+3^{*}$ & & & $0.808 *$ & $4.42 *$ & & \\
\hline & $(0.043)$ & $(0.28 \mathrm{E}-4)$ & 0.015 & 0.860 & $(0.045)$ & $(2.61 E+3)$ & 0.012 & 0.883 & $(0.142)$ & $(0.158)$ & 0.008 & 0.925 \\
\hline \multirow[t]{2}{*}{ Exp. 2} & $0.691 *$ & $1.27 \mathrm{E}-4 *$ & & & $0.713^{*}$ & $4.63 E+3$ & & & $0.697 *$ & $4.21 *$ & & \\
\hline & $(0.049)$ & $(0.40 \mathrm{E}-4)$ & 0.019 & 0.827 & $(0.053)$ & $(2.42 E+3)$ & 0.018 & 0.834 & $(0.182)$ & $(0.283)$ & 0.018 & 0.839 \\
\hline \multirow[t]{2}{*}{ Field } & $0.536 *$ & $6.01 \mathrm{E}-2$ & & & $0.601 *$ & $3.99 \mathrm{E}+3$ & & & $0.559 *$ & $4.58 *$ & & \\
\hline & $(0.039)$ & $(13.4 \mathrm{E}-2)$ & 0.018 & 0.750 & $(0.046)$ & $(2.30 \mathrm{E}+3)$ & 0.014 & 0.813 & $(0.154)$ & $(0.311)$ & 0.020 & 0.768 \\
\hline
\end{tabular}

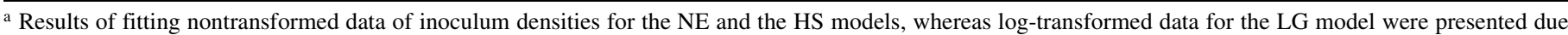
to better fitness of data to the models. RMS $=$ residual mean square, $R^{2}=$ coefficient of determination between observed values and predicted values, and $*$ indicates the parameter estimate was considered to differ from 0 at the $5 \%$ level of significance by $95 \%$ Wald confidence interval. Values in parentheses indicate the asymptotic standard errors for the parameters.

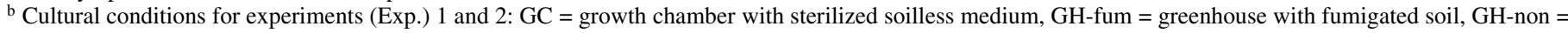
greenhouse with nonfumigated soil, and field = nonfumigated field plot.

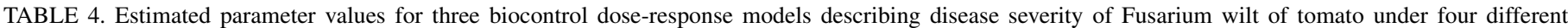
cultural conditions ${ }^{\mathrm{a}}$

\begin{tabular}{|c|c|c|c|c|c|c|c|c|c|c|c|c|}
\hline \multirow[b]{2}{*}{ Condition $^{\mathrm{b}}$} & \multicolumn{4}{|c|}{ Negative exponential (NE) model ${ }^{\mathrm{c}}$} & \multicolumn{4}{|c|}{ Hyperbolic saturation (HS) model ${ }^{\mathrm{c}}$} & \multicolumn{4}{|c|}{ Logistic (LG) model ${ }^{c}$} \\
\hline & $A$ & $c_{n}$ & RMS & $R^{2}$ & $I_{\max }$ & $K_{\mathrm{z}}$ & RMS & $R^{2}$ & $K_{1}$ & $P_{1}$ & RMS & $R^{2}$ \\
\hline \multicolumn{13}{|l|}{ GC } \\
\hline \multirow[t]{2}{*}{ Exp. 1} & $0.994^{*}$ & $2.05 \mathrm{E}-4 *$ & & & $0.999 *$ & $3.35 \mathrm{E}+3 *$ & & & $0.702 *$ & $5.78 *$ & & \\
\hline & $(0.89 \mathrm{E}-3)$ & $(0.25 \mathrm{E}-4)$ & 0.049 & 0.619 & $(6.12 \mathrm{E}-4)$ & $(0.70 \mathrm{E}+3)$ & 0.036 & 0.714 & $(0.083)$ & $(0.122)$ & 0.022 & 0.769 \\
\hline \multirow[t]{2}{*}{ Exp. 2} & $0.995^{*}$ & $969 \mathrm{E}-4$ & & & $0.999 *$ & $1.68 \mathrm{E}+3^{*}$ & & & $0.650^{*}$ & $5.57 *$ & & \\
\hline & $(0.81 \mathrm{E}-3)$ & $(3,020 \mathrm{E}-4)$ & 0.076 & 0.464 & $(3.55 \mathrm{E}-4)$ & $(0.35 E+3)$ & 0.038 & 0.715 & $(0.077)$ & $(0.117)$ & 0.023 & 0.751 \\
\hline \multicolumn{13}{|l|}{ GH-fum } \\
\hline \multirow[t]{2}{*}{ Exp. 1} & $0.994 *$ & $0.23 \mathrm{E}-4 *$ & & & $0.998 *$ & $11.9 \mathrm{E}+3 *$ & & & $0.805^{*}$ & $6.67 *$ & & \\
\hline & $(1.30 \mathrm{E}-3)$ & $(0.03 E-4)$ & 0.028 & 0.734 & $(14.6 \mathrm{E}-4)$ & $(3.61 \mathrm{E}+3)$ & 0.024 & 0.750 & $(0.115)$ & $(0.169)$ & 0.013 & 0.815 \\
\hline \multirow[t]{2}{*}{ Exp. 2} & $0.992 *$ & $2.29 \mathrm{E}-4 *$ & & & 0.997* & $6.26 \mathrm{E}+3^{*}$ & & & $0.550^{*}$ & $6.79 *$ & & \\
\hline & $(1.59 \mathrm{E}-3)$ & $(0.38 \mathrm{E}-4)$ & 0.041 & 0.651 & $(13.0 \mathrm{E}-4)$ & $(1.85 E+3)$ & 0.025 & 0.759 & $(0.056)$ & $(0.155)$ & 0.006 & 0.871 \\
\hline \multicolumn{13}{|l|}{ GH-non } \\
\hline \multirow[t]{2}{*}{ Exp. 1} & $0.359 *$ & $0.96 \mathrm{E}-4$ & & & $0.978 *$ & $97.9 \mathrm{E}+3$ & & & $0.607^{*}$ & $8.12 *$ & & \\
\hline & $(163 \mathrm{E}-3)$ & $(2.48 \mathrm{E}-4)$ & 0.043 & 0.386 & $(174 \mathrm{E}-4)$ & $(59.1 \mathrm{E}+3)$ & 0.034 & 0.496 & $(0.139)$ & $(0.478)$ & 0.015 & 0.689 \\
\hline \multirow[t]{2}{*}{ Exp. 2} & $0.924^{*}$ & $0.06 \mathrm{E}-4$ & & & $0.963 *$ & $30.2 \mathrm{E}+3$ & & & $0.448 *$ & $7.97 *$ & & \\
\hline & (19.1E-3) & $(0.04 \mathrm{E}-4)$ & 0.032 & 0.524 & $(159 \mathrm{E}-4)$ & $(17.7 \mathrm{E}+3)$ & 0.027 & 0.574 & $(0.084)$ & $(0.439)$ & 0.009 & 0.649 \\
\hline \multirow[t]{2}{*}{ Field $^{\mathrm{d}}$} & & & & & $0.735^{*}$ & $40.4 \mathrm{E}+3$ & & & $0.430 *$ & $9.05^{*}$ & & \\
\hline & Failed & Failed & Failed & Failed & (1120E-4) & $(68.9 E+3)$ & 0.027 & 0.380 & $(0.194)$ & (1.438) & 0.022 & 0.506 \\
\hline
\end{tabular}

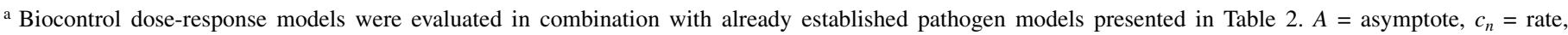
RMS = residual mean-square, $R^{2}=$ coefficient of determination between observed values and predicted values, $*$ indicates the parameter estimate was considered to differ from 0 at the $5 \%$ level of significance by $95 \%$ Wald confidence interval, and values in the parentheses indicate the asymptotic standard errors for the parameters.

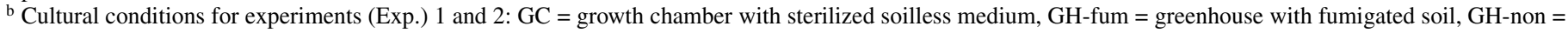
greenhouse with nonfumigated soil, and field = nonfumigated field plot.

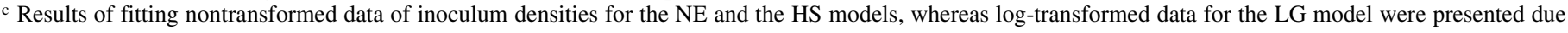
to better fitness of data to the models.

${ }^{\mathrm{d}}$ Failed $=$ failed to converge . 
(greenhouse with nonfumigated soil) with the HS model, and $4.87 \times 10^{5}$ (growth chamber) to $1.12 \times 10^{9}$ (field) with the LG model. Moreover, the ratio of the $\mathrm{ED}_{50}$ parameter for Fo-B2 to the corresponding parameter for the pathogen increased in each of the models as the cultural conditions became less controlled (Table 5).

The LG model, which gave the best fit among each of the four environments, was plotted in relation to observed disease severity data as influenced by the pathogen (Fig. 2A, B, C, and D) and antagonist (Fig. 2E, F, G, and H) dose. In the growth chamber, the dose-response was characterized by response line with a steep slope and high maximal responses for both the pathogen and the antagonist (Fig. 2A and E). For the greenhouse experiment using fumigated soil, the response line of the LG model became somewhat shallower but still showed reasonably effective disease suppression (Fig. 2F). These dose response lines became even shallower in the nonfumigated greenhouse soil and the field experiment (Fig. 2C, D, G, and $\mathrm{H}$ ).

Efficiency of biological control and recovery from vascular tissue. The average effect of the Fo-B2 inoculation on the disease suppression was significant under each cultural condition (Table 6). However, as shown in Figure 1, the efficiencies of both the pathogen and the biocontrol agent were severely influenced by the environments. Rates of recovery of Fo-B2 from the vascular tissues of hypocotyls of inoculated seedlings also were influenced by the cultural condition. For the experiments conducted in the growth chamber and the greenhouse with fumigated soil, recovery of Fo-B2 from the hypocotyls averaged 74 and $70 \%$, respectively (Table 6). However, rates of recovery from seedlings grown in the greenhouse with nonfumigated soil and in the field were lower, averaging 47 and $42 \%$, respectively. The field experiment showed the lowest overall severity of disease in seedlings from which FoB2 was recovered from vascular tissues (Table 6), but also had a high mean disease severity for seedlings that were inoculated with the biocontrol agent. These results indicate that seedlings internally colonized by Fo-B2 suffered from less disease but that FoB2 was less likely to colonize the hypocotyl tissues when the host was grown in a nonfumigated soil.

\section{DISCUSSION}

In this study, the efficiency of biological control of Fusarium wilt of tomato was compared under four environmental conditions: a growth chamber with sterile soilless medium, a greenhouse with fumigated or nonfumigated soil, and nonfumigated field plots. We confirmed that nonpathogenic $F$. oxysporum Fo-B2 is an effective agent for suppression of Fusarium wilt of tomato caused by $F$. oxysporum f. sp. lycopersici $\mathrm{CU} 1$, but that its efficiency differs depending on the cultural conditions. From previous studies $(3,19)$, Fo-B2 has been most effective when applied at inoculum densities that are at least 10 -fold greater than the pathogen under controlled conditions. The results of this study agreed with these findings, showing that this biocontrol agent generally is effective when inoculated antagonist propagules exceed pathogen propagules by an order of magnitude or more.

Three epidemiological dose-response models (NE, HS, and LG) were fit to observed data collected over a range of inoculum densities: $0,1 \times 10^{4}, 1 \times 10^{5}$, and $1 \times 10^{6}$ bud-cells $/ \mathrm{ml}$ of the pathogen, and $0,1 \times 10^{4}, 1 \times 10^{5}, 1 \times 10^{6}$, and $1 \times 10^{7}$ budcells $/ \mathrm{ml}$ of the biocontrol agent. RMS, $R^{2}$, and significance of individual parameters $(P<0.05)$ indicated that all three models fit the data, implying that these models can be a useful tool for describing and characterizing the differences in the dose-response relationships among the four cultural environments (Tables 3 and 4). In all models, as the experimental environment became less controlled (i.e., from the growth chamber to the field plot), the values of parameters for both the pathogen and the biocontrol agent reflected the reduced efficiencies of the propagules. Among these models, the LG model had the best overall fit to data from all conditions. Interestingly, Larkin and Fravel (10) also indicated that the LG model was the best fit for biological control systems of three nonpathogenic Fusarium isolates, whereas bacterial-fungus biocontrol systems often fit better to the NE model $(8,14,20)$. The LG model may be suited for describing biocontrol systems of Fusarium wilts by nonpathogenic Fusarium isolates.

A number of studies have demonstrated the potential for nonpathogenic Fusarium strains as biocontrol agents (4,10-12,1518). In this regard, studies using similar epidemiological models provide parameters that can be used to summarize and compare the effectiveness of these agents. For example, Montesinos and Bonaterra (14) have suggested the use of the ratio of the $\mathrm{ED}_{50}$ parameter of the biocontrol agent to that of the pathogen as such a comparative tool. Their re-analysis of an earlier study of suppression of Fusarium wilt of greenhouse-grown cucumber (12) indicated that the $\mathrm{ED}_{50}$ ratio for the nonpathogenic biocontrol agent, $F$. oxysporum $\mathrm{C} 14$, averaged 9.9 when fit to the HG model (14). Similarly, in the nonfumigated greenhouse environment of this study, Fo-B2 produced an $\mathrm{ED}_{50}$ ratio of 10.1 (Table 5), suggesting that, as an antagonist, the efficiency of Fo-B2 may be comparable with C14. Larkin and Fravel (10), with the LG model, obtained $\mathrm{ED}_{50}$ ratios for nonpathogenic Fusarium strains CS-1, CS2, and Fo47 that averaged 0.002, 0.011, and 641.6, respectively, under greenhouse conditions with a natural, nonfumigated field soil. Conversely, in this study, the experiments with Fo-B2 in the greenhouse in nonfumigated soil resulted in a large $\mathrm{ED}_{50}$ ratio of 5,450 (Table 5, LG model), indicating that it may be an inferior biocontrol agent in a less-controlled environment. Although contrasts like those made above cannot be regarded as absolute, the ability to compare parameters from similar strains reinforces our conclusions concerning the environment to which Fo-B2 is best suited, and provides to us guidance for further research on the pathosystem.

$\mathrm{ED}_{50}$ ratios of inoculum dose of Fo-B2 to the dose of CU1 varied among the cultural environments evaluated in this study. For example, with both the HS and the LG models, the $\mathrm{ED}_{50}$ ratio was smallest in the growth chamber and then increased to its highest values in the field environment. Because the ratio increased as the environmental complexity increased, it suggests that the environmentally related efficiency reduction impacted FoB2 more than CU1. Although one example warrants no generalization, this type of efficiency decline is not surprising in biological control of plant diseases, often underscoring the importance of rigorous scrutiny of biocontrol agents and their potential for effective control. Routine screening of biocontrol agents using high antagonist doses under controlled conditions may not detect these differences, which may be critical for the success or failure of the biological control in commercial production (10).

The causes for the contrasting results among environments were not measured in this study; however, presence or absence of

TABLE 5. Efficiency of biological control of Fusarium oxysporum Fo-B2 under four different cultural conditions as represented by the ratio of the $50 \%$ effective dose $\left(\mathrm{ED}_{50}\right)$ of the antagonist dose to the $\mathrm{ED}_{50}$ of the pathogen dose

\begin{tabular}{lcc}
\hline & \multicolumn{2}{c}{ ED $_{50}$ ratio $^{\mathrm{b}}$} \\
\cline { 2 - 3 } Condition $^{\mathrm{a}}$ & HS model $\left(K_{z} / K_{x}\right)$ & LG model $\left(P_{1} / p_{1}\right)$ \\
\hline $\mathrm{GC}$ & 0.50 & $1.59 . \mathrm{E}+02$ \\
GH-fum & 1.57 & $5.82 . \mathrm{E}+02$ \\
GH-non & 10.1 & $54.5 . \mathrm{E}+02$ \\
Field & 10.1 & $297.2 . \mathrm{E}+02$ \\
\hline
\end{tabular}

${ }^{a}$ Cultural conditions for experiments (Exp.) 1 and 2: GC = growth chamber with sterilized soilless medium, GH-fum = greenhouse with fumigated soil, GH-non = greenhouse with nonfumigated soil, and field $=$ nonfumigated field plot. For GC, GH-fum, and GH-non, averaged values of two experiments were presented.

b Parameter estimates were calculated with nontransformed and log-transformed values for the HS and the LG models, respectively. 


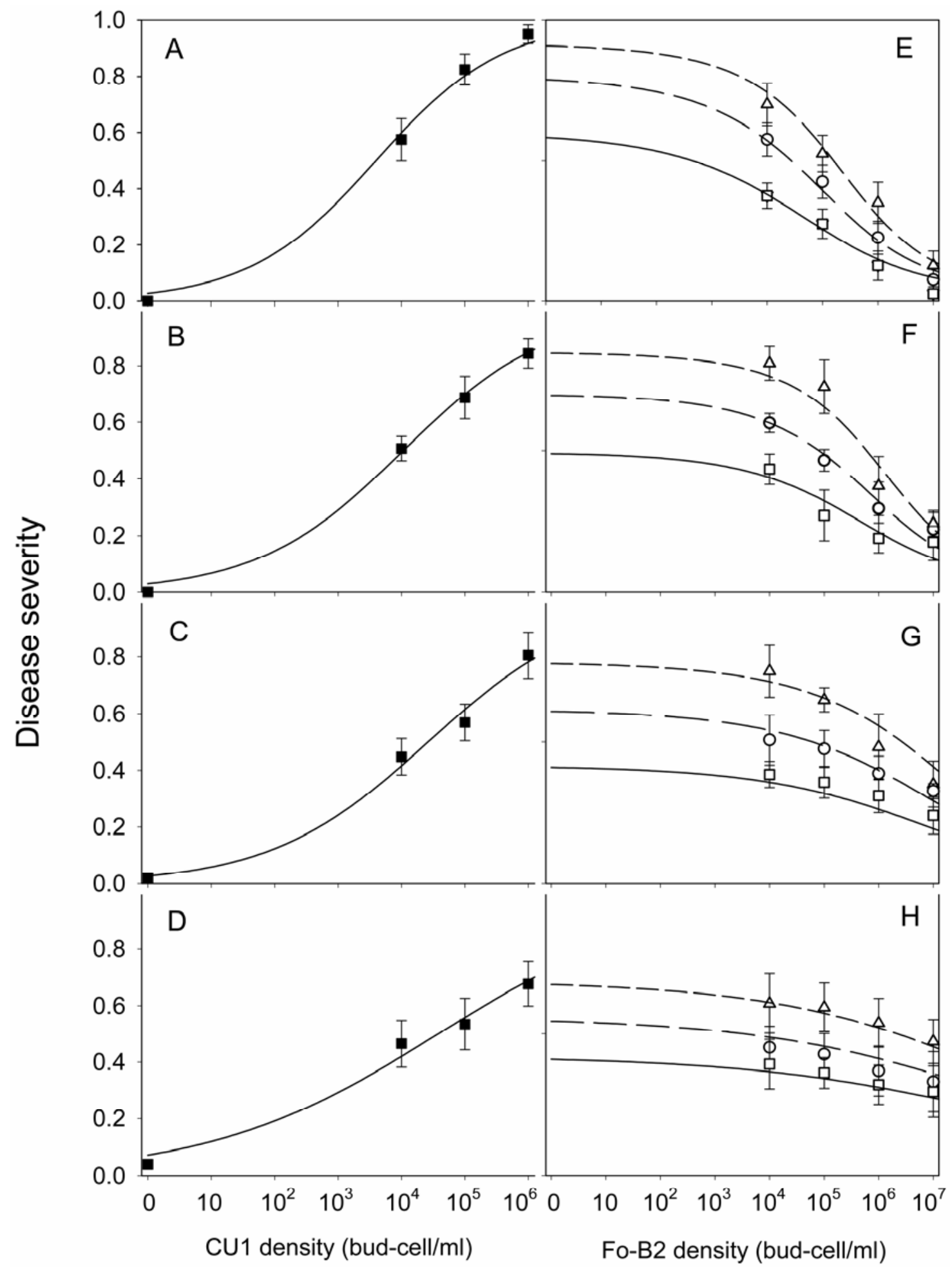

Fig. 2. Disease severities of Fusarium wilt of tomato predicted by the logistic (LG) model in relation to observed data (mean values \pm standard error) under four different cultural conditions as affected by $\mathbf{A}$ to $\mathbf{D}$, increasing pathogen (strain CU1) doses without addition of an antagonist, and $\mathbf{E}$ to $\mathbf{H}$, increasing antagonist doses (strain Fo-B2) with various pathogen doses: $\Delta$ and short-dashed lines, $10^{6}$ bud-cells $/ \mathrm{ml} ; \bigcirc$ and long-dashed lines, $10^{5}$ bud-cells $/ \mathrm{ml}$; and $\square$ and solid lines, $10^{4}$ bud-cells $/ \mathrm{ml}$. A and E, Growth chamber with sterilized soilless medium; $\mathbf{B}$ and $\mathbf{F}$, greenhouse with fumigated soil; $\mathbf{C}$ and $\mathbf{G}$, greenhouse with nonfumigated soil; and $\mathbf{D}$ and $\mathbf{H}$, nonfumigated field plot. The results of the first experiment are presented.

indigenous soil microbes was likely a contributing factor. For example, the greatest difference in the estimated efficiencies of biocontrol occurred between the fumigated and nonfumigated greenhouse conditions, with lesser differences observed between the growth chamber and the fumigated greenhouse environments, and between the nonfumigated greenhouse and field plot environments. These results suggest that the biotic component of the environment, as opposed to physical conditions, may be the most critical regulator of the efficiency of Fo-B2. Studies with other nonpathogenic Fusarium isolates also have highlighted the importance of competition in the successful application of biological control $(2,12)$. Our study also indicated that colonization of the host plant was important for Fo-B2 to be effective. Vascular colonization and the recovery of Fo-B2 from seedling hypocotyls was negatively correlated to severity of disease and, correspondingly, the degree of vascular colonization was most intensive 
TABLE 6. Efficacy of nonpathogenic Fusarium oxysporum Fo-B2 on Fusarium wilt of tomato and its recovery from the vascular tissue of hypocotyls under different environmental conditions

\begin{tabular}{|c|c|c|c|c|c|}
\hline \multirow[b]{2}{*}{ Condition $^{\mathrm{a}}$} & \multicolumn{2}{|c|}{ Mean disease severity of seedlings inoculated with ${ }^{\mathrm{b}}$} & \multirow[b]{2}{*}{ Suppression $(\%)^{\mathrm{c}}$} & \multirow[b]{2}{*}{ Fo-B2 recovery $(\%)^{\mathrm{d}}$} & \multirow[b]{2}{*}{ Disease severity ${ }^{\mathrm{e}}$} \\
\hline & Fo-B2 and CU1 & CU1 only & & & \\
\hline \multicolumn{6}{|l|}{$\mathrm{GC}$} \\
\hline Exp. 1 & $0.317 \pm 0.051(n=96)$ & $0.783 \pm 0.086(n=24)$ & $59.5(P<0.001)$ & 72.9 & $0.220 \pm 0.045(n=70)$ \\
\hline \multicolumn{6}{|l|}{ GH-fum } \\
\hline Exp. 1 & $0.394 \pm 0.046(n=144)$ & $0.679 \pm 0.077(n=36)$ & $42.0(P<0.001)$ & 63.2 & $0.234 \pm 0.032(n=91)$ \\
\hline Exp. 2 & $0.379 \pm 0.040(n=144)$ & $0.707 \pm 0.080(n=36)$ & $46.4(P<0.001)$ & 77.1 & $0.280 \pm 0.029(n=111)$ \\
\hline \multicolumn{6}{|l|}{ Field } \\
\hline Exp. 1 & $0.430 \pm 0.042(n=144)$ & $0.559 \pm 0.093(n=36)$ & $23.1(P=0.014)$ & 41.7 & $0.217 \pm 0.037(n=60)$ \\
\hline
\end{tabular}

${ }^{a}$ Cultural conditions for experiments (Exp.) 1 and 2: GC $=$ growth chamber with sterilized soilless medium, GH-fum = greenhouse with fumigated soil, GH-non $=$ greenhouse with nonfumigated soil, and field $=$ nonfumigated field plot.

b The biocontrol agent, Fo-B2, was inoculated by dipping 2 -week-old tomato seedling roots with $1 \times 10^{4}, 1 \times 10^{5}, 1 \times 10^{6}$, or $1 \times 10^{7}$ bud-cells/ml, whereas the pathogen, CU1, was counter-inoculated with $1 \times 10^{4}, 1 \times 10^{5}$, or $1 \times 10^{6}$ bud-cells $/ \mathrm{ml}$.

${ }^{c}$ Disease suppression by Fo-B2 inoculation; $P=$ Probability of null hypothesis between the disease severities of Fo-B2 inoculated and noninoculated seedlings by Mann-Whitney U test.

${ }^{d}$ Fo-B2 recovery rate from vascular tissue of inoculated seedlings. Number of Fo-B2 recovered seedlings/number of total seedlings $\times 100$. Dead seedlings were counted negative.

${ }^{\mathrm{e}}$ Mean disease severity (mean $\pm 95 \%$ confidence limit) of seedlings if Fo-B2 were recovered from vascular tissues.

when Fo-B2 was inoculated under nearly sterile conditions. In contrast, the degree of host colonization by Fo-B2 was reduced in nonsterile soils (Table 6). Thus, we hypothesize that competition from indigenous microbes slows the rate of vascular colonization by antagonist populations, which directly affects the observed degree of disease suppression.

Importantly, these results suggest that extensive root colonization by Fo-B2 under controlled conditions prior to exposure to indigenous soil microbes potentially could improve the efficiency of this biocontrol agent, even for uncontrolled environments. For Japan, the use of transplants is common under normal tomato production operations and, therefore, the integration of an antagonist such as Fo-B2 into the production system could be straightforward. Indeed, it should be noted that the pathogen inoculation method used in this study was extreme compared with the practical situation that allows tomato seedlings to become diseased via naturally dispersed pathogen propagules. Consequently, if Fo-B2 is introduced into soilless medium at the time of seeding and allowed to establish and colonize tomato seedlings during a nursery period, the degree of suppression obtained by Fo-B2 could be more effective than observed in this study.

In summary, the efficiency of the biocontrol agent Fo-B2 in suppressing Fusarium wilt of tomato varied under different cultural environments. The ratios of an $\mathrm{ED}_{50}$ parameter for Fo-B2 to that of the pathogen CU1 based on their dose-response relationships increased as the environment became less controlled, suggesting that environmentally related efficiency reduction impacted the biocontrol agent more than the pathogen. Recovery of Fo-B2 from seedling hypocotyls and severity of disease indicated that Fo-B2 was most effective when it colonized vascular tissues of the host intensively, and the degree of colonization by the beneficial organism was greatly reduced when soil was not sterile. These results suggest that indigenous populations of soil microorganisms negatively influenced the efficiency of Fo-B2 inoculations; therefore, early establishment of the fungal antagonist in tomato seedlings prior to outplanting may improve the efficacy of this biological control strategy.

\section{ACKNOWLEDGMENTS}

This research was supported in part by Grants-in-Aid for Scientific Research (14560037) from the Japan Society for the Promotion of Science. We thank K. Sakamoto and S. Ushio for the soil property analyses and $\mathrm{K}$. Ishiguro for discussion of epidemiological models.

\section{LITERATURE CITED}

1. Adams, P. B. 1990. The potential of mycoparasites for biological control of plant pathogens. Annu. Rev. Phytopathol. 28:59-72.

2. Alabouvette, C., Lemanceau, P., and Steinberg, C. 1993. Recent advances in the biological control of Fusarium wilts. Pestic. Sci. 37:365-373.

3. Amemiya, Y. 1996. Induction of disease resistance in plants by root colonizing microorganisms. PSJ Soilborne Dis. Workshop Rep. 18:91-96.

4. Fuchs, J.-G., Moënne-Loccoz, Y., and Défago, G. 1997. Nonpathogenic Fusarium oxysporum strain F047 induces resistance to Fusarium wilt in tomato. Plant Dis. 81:492-496.

5. Fukui, R., Campbell, G. S., and Cook, R. J. 1994. Factors influencing the incidence of embryo infection by Pythium spp. during germination of wheat seeds in soils. Phytopathology 84:695-702.

6. Gnanamanickam, S. S., Vasudevan, P., Reddy, M. S., Kloepper, J. W., and Défago, G. 2002. Principles of biological control. Pages 1-9 in: Biological Control of Crop Diseases. S. S. Gnanamanickam, ed. Marcel Dekker, Inc., New York.

7. Johnson, K. B. 1994. Dose-response relationships and inundative biological control. Phytopathology 84:780-784.

8. Johnson, K. B., and DiLeone, J. A. 1999. Effect of antibiosis on antagonist dose-plant disease response relationships for the biological control of crown gall of tomato and cherry. Phytopathology 89:974-980.

9. Komada, H. 1975. Development of a selective medium for quantitative isolation of Fusarium oxysporum from natural soil. Rev. Plant Prot. Res. 8:114-124.

10. Larkin, R. P., and Fravel, D. R. 1999. Mechanisms of action and doseresponse relationships governing biological control of Fusarium wilt of tomato by nonpathogenic Fusarium spp. Phytopathology 89:1152-1161.

11. Larkin, R. P., Hopkins, D. L., and Martin, F. N. 1996. Suppression of Fusarium wilt of watermelon by nonpathogenic Fusarium oxysporum and other microorganisms recovered from a disease-suppressive soil. Phytopathology 86:812-819.

12. Mandeel, Q., and Baker, R. 1991. Mechanisms involved in biological control of Fusarium wilt of cucumber with strains of nonpathogenic Fusarium oxysporum. Phytopathology 81:462-469.

13. Miwa, C., Yoshinaga, H., Shishido, M., and Amemiya, Y. 1999. Effect of plant components on the ability of disease suppression of nonpathogenic Fusarium oxysporum. (Abstr.) Ann. Phytopathol. Soc. Jpn. 65:357.

14. Montesinos, E., and Bonaterra, A. 1996. Dose-response models in biological control of plant pathogens: An empirical verification. Phytopathology 86:464-472.

15. Ogawa, K., and Komada, H. 1984. Biological control of Fusarium wilt of sweet potato by non-pathogenic Fusarium oxysporum. Ann. Phytopathol. Soc. Jpn. 50:1-9.

16. Oyarzun, P. J., Postma, J., Luttikholt, A. J. G., and Hoogland, A. E. 1994. Biological control of foot and root rot in pea caused by Fusarium solani with nonpathogenic Fusarium oxysporum isolates. Can. J. Bot. 72:843852. 
17. Paulitz, T. C., Park, S., and Baker, R. 1987. Biological control of $F u$ sarium wilt of cucumber with nonpathogenic isolates of Fusarium oxysporum. Can. J. Microbiol. 33:349-353.

18. Reid, T. C., Hausbeck, M. K., and Kizilkaya, K. 2002. Use of fungicides and biological controls in the suppression of Fusarium crown and root rot of asparagus under greenhouse and growth chamber conditions. Plant Dis. 86:493-498.
19. Shishido, M., Miwa, M., and Amemiya, Y. 1999. An empirical verification of biocontrol dose-response models using nonpathogenic Fusarium oxysporum to Fusarium wilt of tomato. (Abstr.) Ann. Phytopathol. Soc. Jpn. 65:658-659.

20. Smith, K. P., Handelsman, J., and Goodman, R. M. 1997. Modeling doseresponse relationships in biological control: Partitioning host responses to the pathogen and biocontrol agent. Phytopathology 87:720-729. 